with caution. Randomised studies are needed to achieve more information about efficacy and safety.

\section{PO-0483a THE APPLICATION OF NEXT GENERATION SEQUENCING IN CLINICAL DIAGNOSIS OF NEONATAL SEIZURE}

W Zhou, Y Lin, L Hu, L Wang. Department of Neonatology, Children's Hospital of Fudan University, Shanghai, China

10.1136/archdischild-2014-307384.1125

Objective For 26 patients with neonatal seizure, we designed a panel with 741 seizures related genes and performed target sequencing.

Methods The subjects were consisted of 26 neonatal convulsions with unknown cause. Among them, 18 (69.2\%) were female and 8 (30.8\%) were male. 741 genes coding regions capture was performed using the SureSelect Target Enrichment kit from Agilent. Results Overall, we identified 87,920 SNVs in 26 patients. Of the 1497 variants with unknown significant (VUSs), 3 were nonsense variants, 3 were in splicing site, and 33 missense variants were predicted to be damage by SIFT and PolyPhen2. These 39 variants affected 32 genes were found in 19 probands. We identified pathogenetic mutations in 7 cases (26.9\%).

Conclusion The sequencing analysis of 741 seizures related genes was performed in 26 patients with neonatal convulsions. We identified pathogenetic mutation in 6 cases $(23.1 \%)$ which may contribute to the selection of specific medication treatment.

\section{PO-0483b REVISED NICHD DEFINITION FOR BRONCHOPULMONARY DYSPLASIA (BPD) PREDICTS NEURODEVELOPMENTAL IMPAIRMENT (NDI) AT 2 YEARS CORRECTED AGE IN SINGAPORE}

W Poon, J Yang. Neonatal and Developmental Medicine, Singapore General Hospital, Singapore, Singapore

\subsection{6/archdischild-2014-307384.1126}

Aim To determine how well the revised NICHD criteria for bronchopulmonary dysplasia (BPD) predicts neurodevelopmental impairment (NDI) and growth impairment at 2 years corrected age (CA) in the contemporary era in a multi-ethnic Asian population.

Methods Longitudinal cohort study.

Setting Singapore General Hospital, a regional tertiary teaching hospital.

Participants Preterm infants with birthweight $<1250$ grammes, admitted from Jan 12009 to Dec 312010 with BPD compared to no BPD.

Outcome measures Neurodevelopmental and growth outcomes. Further multiple logistic regression were performed on factors, particularly modifiable factors, associated with BPD, which may be associated with NDI.

Results Out of 72 infants who satisfied the inclusion, 60 survived the primary hospitalisation. 46 children (77\% of survivors) returned for Bayley III at 2 years, and 44 completed the assessment. BPD children had significantly lower birthweight and were more likely to be from a multiple pregnancy, to require high frequency oscillatory ventilation, to have pneumothorax, hemodynamically significant PDA (HSPDA), nosocomial sepsis and pneumonia, longer duration of ventilation and oxygen. They were also more likely to have ROP and NEC, but not IVH. BPD children were more likely to have NDI (defined by cognitive, language or motor scores < 70) OR 6.3 (95\% CI 1.136.7). No significant differences were found for growth parameters at 2 years CA. Multiple logistic regression revealed independent association of HSPDA with NDI.

Conclusion NICHD definition of BPD significantly predicts NDI at 2 years CA. HSPDA was independently associated with NDI.

\section{PO-0483C PUNCTATE LESIONS ON MR IMAGES IN PRETERM INFANTS AT TERM CORRECTED AGE}

${ }^{1}$ A Ederies, ${ }^{1} \mathrm{P}$ Nongena, ${ }^{1} \mathrm{~V}$ Wardley, ${ }^{1} \mathrm{~N}$ Hayward, ${ }^{2} \mathrm{~J}$ Wurie, ${ }^{1} \mathrm{~N}$ Gonzalez-Cinca, ${ }^{2} \mathrm{D}$ Azzopardi, ${ }^{2} \mathrm{~S}$ Counsell, ${ }^{2} \mathrm{M}$ Rutherford, ${ }^{3} \mathrm{~N}$ Kennea, ${ }^{2} \mathrm{~A}$. D. Edwards on behalf of the ePrime study. ${ }^{1}$ Paediatrics, Imperial College London, London, UK; ${ }^{2}$ Centre for the Developing Brain, Kings College London, London, UK; ${ }^{3}$ Neonatology, St George's Healthcare NHS Trust, London, UK

\subsection{6/archdischild-2014-307384.1127}

Introduction We studied Punctate Lesions detected by cerebral Magnetic Resonance (MR) in a large group of preterm infants recruited to the Evaluation of Preterm Imaging Programme (ePrime).

Methods We studied 511 of 2133 eligible infants cared for in 13 neonatal units including 5 Perinatal Centre. 254 were male and 84 from multiple pregnancies. Median (range) gestational age (GA) was 30 (23-32) weeks and birthweight 1270 (552$3160)$ g. T1 and T2 weighted MR images were obtained at 3844 weeks GA in 479 and 44-60 weeks GA in 32 infants, and reported using conventional diagnostic criteria.

Results Neuroradiological analysis detected punctate lesions in 98 infants (19\%), of whom 42 (8\%) had more than 20 lesions. Preliminary analysis found no relation with more extreme prematurity, multiple pregnancy, birthweight, surfactant or antenatal steroid therapy, length of respiratory support or treatment for patent ductus arteriosus. No punctate lesions were reported on contemporaneous cranial ultrasonography, and 87/98 of those scans were reported as normal.

Conclusions Punctate lesions are common, of unclear aetiology, and not detected by ultrasonography.

\section{PO-0483d NO NEUROPROTECTIVE EFFECTS OF CANNABIDIOL AFTER SEVERE HYPOXIA-ISCHEMIA IN NEWBORN PIGLETS}

${ }^{1} \mathrm{HT}$ Garberg, ${ }^{1} \mathrm{MU}$ Huun, ${ }^{2} \mathrm{~J}$ Escobar, ${ }^{3} \mathrm{~J}$ Martinez Orgado, ${ }^{1} \mathrm{R}$ Solberg, ${ }^{1} \mathrm{OD}$ Saugstad. ${ }^{1}$ Department of Pediatric Research, Oslo University Hospital, Oslo, Norway; ${ }^{2}$ Research Unit, Health Research Institute Hospital La Fé, Valencia, Spain; ${ }^{3}$ Experimental Unit, Pediatric Department University Hospital Puerta de Hierro Majadahonda, Madrid, Spain

\subsection{6/archdischild-2014-307384.1128}

Background and aim Hypothermia is limiting neurological sequela after perinatal asphyxia. Still a significant number of infants have minimal effect of the treatment. Adjuvant neuroprotective strategies are therefore needed. In animal studies the phytocannabinoid Cannabidiol (CBD) has shown great promise as a 


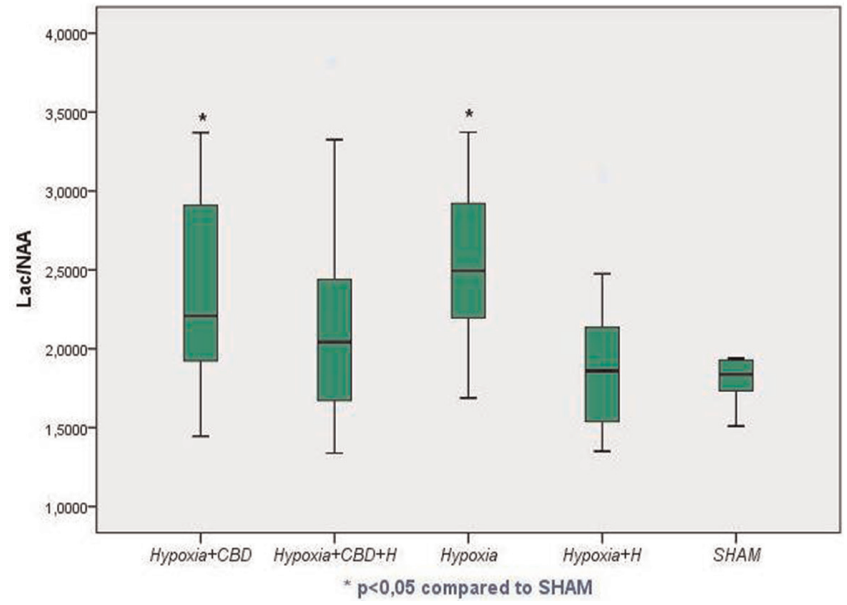

Abstract P0-0483d Figure 1

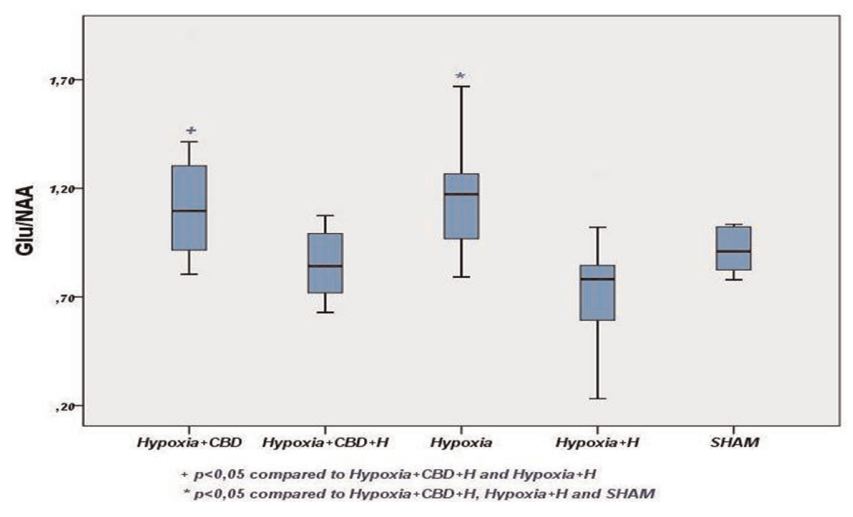

Abstract PO-0483d Figure 2

neuroprotective agent. The aim of this study was to explore the neuroprotective properties of CBD after hypoxia ischemia in newborn piglets.

Materials and method 54 anaesthetised piglets (age 12-36 h) were randomised to either undergo global hypoxia $(n=48)$ until the base excess reached $-20 \mathrm{mmol} / \mathrm{L}$ or the mean arterial blood pressure dropped below $20 \mathrm{~mm} \mathrm{Hg}$ or to the SHAM group $(n=6)$. After hypoxia piglets were randomised to the different study groups : Hypoxia+CBD $(1 \mathrm{mg} / \mathrm{kg})(\mathrm{n}=12)$, Нypo$\mathrm{xia}+\mathrm{CBD}(1 \mathrm{mg} / \mathrm{kg})+$ hypothermia $(\mathrm{n}=12)$, hypoxia $(\mathrm{n}=12)$ or hypoxia+hypothermia $(n=12) .9,5 \mathrm{~h}$ after end of hypoxia the piglets were euthanized and samples from hippocampus were snap frozen in liquid nitrogen. Levels of lactate (lac), n-acetylaspartate (NAA) and glutamate (glu) were measured by protonmagnetic-resonance-spectroscopy $\left(\mathrm{H}^{ \pm}-\mathrm{MRS}\right)$ - and ratios predictive of neurodevelopmental outcome after hypoxic-ischaemic encephalopathy in newborns where calculated (lac/NAA and glu/ NAA). Outliers $>2,5 \mathrm{SD}$ away from mean were removed before analysis.

Results

Discussion Hypoxia significantly increased both Lac/NAA and Glu/NAA ratios. Hypothermia groups were comparable to SHAM while there were no significant effects of CBD on these MRS biomarkers. The difference in the way of inducing and the severity of hypoxia-ischemia in our model might explain this lack of effect compared to previously published studies.

\section{Neonatal Cardiovascular}

\section{PO-0484 NEONATAL THYROTOXICOSIS WITH SEVERE SUPRAVENTRICULAR TACHYCARDIA: CASE REPORT AND REVIEW OF THE LITERATURE}

${ }^{1}$ A Abbasoglu, ${ }^{1} \mathrm{~A}$ Ecevit, ${ }^{1} \mathrm{AU}$ Tugcu, ${ }^{2}$ Erdogan, ${ }^{3} \mathrm{~S}$ Tulgar Kinik, ${ }^{1} \mathrm{~A}$ Tarcan. ${ }^{1}$ Neonatology, Baskent University, Ankara, Turkey; ${ }^{2}$ Pediatric Cardiology, Baskent University, Ankara, Turkey; ${ }^{3}$ Pediatric Endocrinology, Baskent University, Ankara, Turkey

\subsection{6/archdischild-2014-307384.1129}

Background and aims Neonatal thyrotoxicosis is a rare condition caused by the transplacental passage of thyroid stimulating immunoglobulins from mothers with Graves' disease. We report a case of neonatal thyrotoxicosis with concurrent supraventricular tachycardia.

Case Report The female infant, who was born by ceasarean section due to breech delivery and meconium in the amniotic fluid at 36 weeks of gestation, presented with tachycardia on day 7 . Her heart rate was between $260-300$ beats/minute, and electrocardiogram revealed ongoing supraventricular tachycardia. Sotalol was effective after two cardioversions in maintaining sinus rhytm. Our patient was diagnosed to have thyroid storm due to thyrotoxicosis. Intensive medical therapy was started with 10 $\mathrm{mg} / \mathrm{kg} /$ day of propylthiouracil, 1 drop of Lugol's iodine solution three times per day, $2 \mathrm{mg} / \mathrm{kg} / \mathrm{day}$ propranolol, and $2 \mathrm{mg} / \mathrm{kg} / \mathrm{day}$ of oral prednisolone. After the diagnosis of neonatal thyrotoxicosis, the mother in our case was found out to have hyperthyroidism with TSH: $0.035 \mu \mathrm{IU} / \mathrm{mL}$ (normal: 0.35 - 4.94). She was immediately started methimasole treatment.

Conclusions The purpose of presenting this patient is to emphasise the importance of prenatal care and follow-ups. Obstetricians, endocrinologists, and paediatricians need to work together for better management of Graves' disease associated pregnancies.

\section{P0-0485 CEREBRAL BLOOD FLOW AND OXYGENATION CHANGES FOLLOWING BLOOD TRANSFUSION IN PRETERM INFANTS}

1」 Banerjee, ${ }^{2} \mathrm{TS}$ Leung, ${ }^{1} \mathrm{~N}$ Aladangady. 'Department of Neonatology, Homerton University Hospital, London, UK; ${ }^{2}$ Department of Medical Physics and Bioengineering, University College London, London, UK

\subsection{6/archdischild-2014-307384.1130}

Background and aims We have shown blood transfusion (BT) significantly reduces cerebral blood flow and improves cerebral tissue oxygenation in preterm infants during the first week of life . ${ }^{1}$

Aim To study the effect of BT on cerebral blood flow and oxygenation during the 2 nd to 4 th week of life in preterm infants.

Methods Pre and post-BT Anterior Cerebral Artery (ACA) peak systolic velocity, mean velocity, resistance index (RI) and pulsatility index (PI), and Superior Vena Cava (SVC) flow were measured using Doppler USS. Pre, during and post-BT cerebral oxygenation were measured using Near Infra-Red Spectroscopy (NIRO 300).

Pre and post-BT measurements were compared by paired ttest using SPSS 22.0.

Results 21 preterm infants with median (range) gestational age of 25(23-30) weeks, birth weight 805(630-1250) grams, chronological age 14(8-27) days and pre-BT Haemoglobin 10.3(7.712.2) $\mathrm{g} / \mathrm{dl}$ were studied. 